\title{
Entre lo pagano y lo cristiano. Espacios funerarios romanos y tardoantiguos en Galicia
}

\author{
Between pagan and Christian. Roman and Late Antique funerary sites in Galicia \\ http://dx.doi.org'/10.15304/gall.37.5705
}

Laura Blanco-Torrejón

Universidade de Santiago de Compostela

laura.blanco.torrejon@rai.usc.es

\section{Resumen}

El presente artículo realiza una breve aproximación al mundo funerario gallego a través del estudio de 48 necrópolis repartidas por el territorio de esta comunidad y enmarcadas entre los siglos I a. C. y VI d. C. La investigación constató la abundancia de necrópolis de inhumación tardoantiguas y distribuidas, principalmente, en la costa pontevedresa. Asimismo, dichos espacios funerarios presentan, en su gran mayoría, relaciones espaciales con castros y civitates/núcleos portuarios. Por último, queremos hacer hincapié en la notable ausencia de datos a la que hemos tenido que hacer frente y que ha impedido en muchos casos el completo estudio de determinados yacimientos.

Palabras clave: Arqueología funeraria, necrópolis, cremación, inhumación, Alto Imperio, tardoantigüedad, Alta Edad Media, Galicia

\begin{abstract}
This paper makes an approach to the Galician Roman funerary world through the study of 48 cemeteries between the $1^{\text {st }}$ century B.C. and the $6^{\text {th }}$ century A.D. The research brought to light the vast amount of late antique inhumation cemeteries and its distribution around the Pontevedra's coast. Moreover, these funerary areas had spatial relations with hillforts and civitates/port towns. Finally, we want to highlight the significant absence of information which has hindered the research of certain graveyards.
\end{abstract}

Keywords: Funerary archaeology, cemeteries, cremation, inhumation, Roman imperial period, Late Antiquity, Early Medieval Ages, Galicia. 


\section{INTRODUCCIÓN}

El mundo funerario romano y tardoantiguo gallego cuenta con amplias y notables referencias repartidas a lo largo de todo el territorio, pero su análisis ha sido muy variable y desigual. De forma habitual, las investigaciones desarrolladas han tendido hacia estudios individualizados, centrados en una tumba o yacimiento concreto; sin que exista, a día de hoy, cuadros de síntesis general como los realizados por Desiderio Vaquerizo (2007, 2011) en el caso cordobés, Enrique Gutiérrez Cuenca (2015) para Cantabria o Mário Jorge Barroca (2010-11) en el norte de Portugal, entre otros.

De la misma forma, apenas existen trabajos en esta comunidad que aborden de forma sistemática las transformaciones ocurridas en los comportamientos funerarios a partir de la cristianización y el fin del Imperio romano, a diferencia de otras áreas en las que la riqueza de los ajuares "germánicos" suscitó a lo largo del siglo XX un notable interés por parte de los arqueólogos del período tardoantiguo (AZKARATE GARAI-OLAUN 2002).

Paralelamente, la arqueología funeraria gallega destaca por un importante desarrollo de los estudios osteológicos, entre los que podemos subrayar los llevados a cabo por Olalla López-Costas (2012, 2015; LÓPEZ-COSTAS, SÁNCHEZ-PARDO 2016) o Xosé Carro Otero $(1986,1987,1996)$, que están definiendo el carácter social y demográfico de estas poblaciones como muestran los últimos resultados de A Lanzada, San Xiao de Moraime, Iria Flavia o San Vítor de Barxacova (LÓPEZ-COSTAS, SÁNCHEZ-PARDO 2016:51).

Por otro lado, la evolución de esta arqueología está vinculado en parte al propio devenir de los estudios en arqueología romana y tardoantigua, la cual esta mostrando un dinamismo que rompe con las tradicionales visiones de "periferia" y "debilidad" del extremo noroeste peninsular. Entre dichas investigaciones podemos destacar los trabajos de Fermín Pérez Losada sobre la Vila de Toralla (2005, 2007, 2008) o las campañas arqueológicas realizadas en los años 80 y 90 del siglo XX, y posteriormente entre 2006 y 2008 que revelaron una ocupación continuada desde el siglo I-VII d. C. en la ciudad de Vigo (CONSTELA DOCE 2008; HIDALGO CUÑARRO 1990-1991; FERNÁNDEZ FERNÁNDEZ 2014; PÉREZ LOSADA 2002). En este sentido son también importantes aquellos que abordan la cristianización de Galicia, como los llevados a cabo por Manuel C. Diaz y Diaz (1991, 1993), José C. Sánchez Pardo (2012, 2013, 2014) en lo referente a las primeras iglesias y organización eclesiástica y Diego Piay Augusto sobre el surgimiento y expansión del priscilianismo en esta comunidad (2011, 2016).

Por último, para analizar correctamente este tema se hace necesario partir del concepto de "arqueología de la muerte", término acuñado por la New Archaeology en los años 70 del siglo XX para referirse a todo aquel elemento vinculado al individuo $\mathrm{y}$, al mismo tiempo, a la sociedad que lo rodea, creando una serie de ideas y conceptos sobre el propio significado de la muerte. En este sentido, la muerte por sí misma no es solo un conjunto de enterramientos agrupados en un espacio más o menos amplio, sino que también es parte del pensar y sentir de los individuos. Es su posición social, nivel económico, valores, moral, tradiciones, y, por supuesto, el dolor por una pérdida. Apoyándose en ello, la arqueología de la muerte dibuja un paisaje de tres esferas interconectadas (físico, social y simbólico) donde se hace necesario el estudio en conjunto de las mismas (GARCÍA QUINTELA 2014, 2015). 


\section{ConCEPCIÓN DE LA MUERTE EN EL MUNDO ROMANO}

Antes de comenzar con la revisión de los datos arqueológicos del caso gallego, es necesario presentar brevemente los rasgos principales de la concepción dela muerte en el mundo romano, para comprender cómo esta afectará a las costumbres funerarias del Noroeste peninsular.

La muerte en el mundo romano era concebida como un sueño eterno generado por Hypnos y la tumba, una domus aeterna donde alma (en forma de sombra) y cuerpo se mantenían en relación directa. Se trata de un concepto de muerte muy vinculado al de memoria y recuerdo, pues sin ellos la persona fallecida desaparecía por completo. Un claro ejemplo sería todos aquellos epígrafes funerarios que aportan información de la edad, cursus honorum, oficios, etc. del fallecido/-a y al mismo se convierten en elementos de conmemoración y de recordatorio permanente sobre su figura. (RUIZ TRAPERO et al., 2003: 23-25).

Ya en época republicana se incorporaron las figuras de lemures/larvae como formas que podrían adoptar los antepasados para ayudar a sus descendientes y, a partir del siglo I a. C., los Manes como almas individuales y apotropaicas. (VAQUERIZO GIL 2007: 136). Todo este pensamiento tuvo su reflejo inmediato en el funus, regulado por el ius pontificium, y en la legislación imperante donde se entendía la voluntad del fallecido como lex sacra, sin ninguna validez en el derecho civil, pero situada al mismo tiempo por encima de él (REMESAL RODRÍGUEZ 2001: 370)

Paralelamente, todos los enterramientos (incluyendo las cremaciones) debían realizarse fuera del espacio urbano', tal y como se estipulaba en las XII Tablas ("Hominem mortuum in urbe ne sepelito neve urito" XII Tab. 10.1.1). Los fallecidos podían ser depositados tanto en su propia propiedad o de familiares como en los recintos destinados a dicha tarea.

De esta forma el pomerium quedó configurado como una frontera entre vivos y muertos, creando una topografía funeraria similar a la de sus antecesores etruscos. Mientras que los monumentos de familias pudientes e importantes para la ciudad se situaban en las puertas de esta, cruces de vías y áreas de espectáculos, los demás cuerpos eran repartidos por el resto de terreno dibujando un crecimiento horizontal y alejándose progresivamente de la ciudad. De esta forma, se podría aplicar la idea de que la distancia a la ciudad era inversamente proporcional al tiempo de fallecimiento del individuo; pero debemos tener siempre presente que, si el fallecido era un alto cargo de la ciudad o pertenecía a una familia adinerada, la distancia y el tiempo perdían esa relación, pues solo primaría la condición de situarse en un lugar visible para el resto de la ciudadanía.

Junto a los enterramientos individuales coexistían fosas comunes (puticuli) en las que las instituciones y autoridades romanas encargadas depositaban los cuerpos de todos aquellos que no podían costearse una sepultura, carecían de propiedad suficiente como para ser enterrados allí, se hallaban sin ningún familiar, etc. Casos como los de

1 Mención aparte serían los casos de infantes (menores de 10 años -posteriormente se redujo a 2 años-), vestales y determinadas personalidades que podían ser enterradas intramuranae. (FERNÁNDEZ FERNÁNDEZ 1993). 
Emerita Augusta, Corduba o Tarraco (SEVILLA CONDE 2014:83), entre otras, nos demuestran que la propia sociedad romana no dudaba en dar sepultura a estas personas como respuesta a una creencia en seres de ultratumba que, si podían, regresaban del Hades para atormentar a los vivos.

En torno al siglo III d. C. se produjo una crisis religiosa dentro del seno del Imperio, pues los antiguos dioses no eran capaces de satisfacer las necesidades de las masas, lo que permitió la expansión del cristianismo. Este penetró a través de las vías de comunicación y aprovechó la marcha de determinados sectores urbanos a las villas rurales. El vacío dejado por las élites urbanas fue ocupado por estos nuevos religiosos que acabaron conformando una jerarquía eclesiástica protegida por el emperador desde el $395 \mathrm{~d}$. C. (AVIAL-CHICHARRO, BLANCO-TORREJÓN 2017: 478)

Una de las corrientes religiosas que se impuso en algunas zonas del Imperio (entre ellas el Norte peninsular) fue el priscilianismo (PIAY AUGUSTO 2016; DÍAZ Y DÍAZ 1991). Este acontecimiento se tradujo en la entrada de ideas orientalistas, así como una vuelta al simbolismo prerromano (culto al mundo astral); también abogaba por el rechazo a los bienes materiales en defensa de la virtud y riqueza individual, concedía un papel religioso a la mujer y propugnaba el ayuno y las reuniones secretas. Destacaba por su elevada posición dentro de la sociedad, ya que muchos de sus miembros pertenecían a las élites locales y mantenían una estrecha relación con personalidades influyentes de la ciudad.

Con el devenir de los años y a partir del siglo $\mathrm{V}$, se empezó a entender la muerte como algo próximo y familiar. Ph. Ariès la denominó mort apprivvoisée y se inició con la reintroducción de los fallecidos dentro de los muros de la ciudad (enterramientos in ambitos murorum). (AZKARATE GARAI-OLAUN 2002: 121)

Un elemento importante relacionado con estos enterramientos intramuros fue la presencia de reliquias de santos. Tal era su poder que las misas en favor de los fallecidos no se harían en el camposanto sino dentro de las propias iglesias y basílicas que contenían dichas reliquias (denominados enterramientos ad sanctos). Esto responde al vínculo existente entre reliquia-santo-"vuelta a la vida", es decir, tras el fallecimiento del mártir su figura renace en forma de divinidad y su expresión más cercana al fiel es a través de sus reliquias. (CASTELLANOS 1996: 17-18)

De esta forma permanecía inmutable la idea romana de jerarquización social funeraria, pero en este caso tratando de que los enterramientos se localizasen lo más próximo posible a los emblemas de la cristiandad: los mártires y las reliquias de santos. Nos encontramos en un momento en el que solo los más pudientes podían ser enterrados más cerca del santo/mártir, una relación que recuerda a la de aquellos enterramientos próximos a puertas y vías. De nuevo se hace presente la visibilización de la muerte y el miedo a ser olvidado (miedo a una damnatio memoriae que era solventado a través de las misas posteriores al fallecimiento, oraciones...).

Con ello uno de los mayores rasgos distintivos de este momento bajo influencia cristiana frente a la etapa romana era que dicho miedo al olvido se transformó poco a poco en miedo a la muerte. El caso más representativo son los testamentos que, a partir de época medieval, se hacen constantes como medio de mantener vivo y completo el patrimonio de un individuo. 
Por tanto, vemos como la concepción de la muerte se ha desarrollado a lo largo de la Historia bajo dos etiquetas: miedo y visibilización. Por un lado, el ciudadano romano era capaz de controlar ese miedo utilizando la figura del destino y la "divinización" posterior a la muerte, para después pasar a un miedo dominado por un tercero, la Iglesia; por otro lado, tanto en época romana como bajo el cristianismo ser visible tras la muerte era sinónimo de tener poder. Se busca la necesidad de recordar a cada uno de los conciudadanos quién fue aquella persona y qué hizo a lo largo de su vida.

\section{3. Ámbito de ESTUdio y METOdOLOGía}

$\mathrm{Al}$ inicio de este artículo se hacía referencia a la existencia de una abundante presencia de yacimientos funerarios en Galicia, pero cuyo estudio se encontraba disperso y muy desigual. Nos hallamos ante una situación, heredada desde los años 90 del siglo XX, de campañas arqueológicas con carácter de urgencia y, en un alto porcentaje, sobre suelo urbanizado. Este condicionante supone un elemento a tener en cuenta a la hora de analizar objetivamente los datos, ya que la distribución de necrópolis que se ha observado responde en parte a dicho fenómeno (p.ej. la existencia de un alto número de espacios funerarios en ámbitos costeros altamente antropizados, como ocurre en las Rías Baixas, o en lugares afectados por la creación de líneas ferroviarias y/o carreteras).

Por otro lado, y debido al amplio territorio que ocupaba la antigua provincia romana de Gallaecia, se decidió acotar dicho espacio a la actual Comunidad Autónoma de Galicia. De esta forma ciertos yacimientos que hoy en día se encuentran en el norte de Portugal y occidente de Asturias y León quedan fuera del estudio, aunque deben tenerse en cuenta para la comprensión global del desarrollo funerario en esta comunidad.

Cronológicamente la investigación se realizó bajo la horquilla temporal de los siglos I a. C. hasta el VI d. C. Esta amplia secuencia responde a que, en muchos casos, existen necrópolis cuyo inicio se da en los siglos II-III d. C. y su uso se sigue manteniendo a lo largo de los siglos IV/V d. C. Este tipo de espacios en los que perdura la función de enterramiento (en algunos incluso hasta época moderna -p.ej. Adro Vello, O Grove-) nos está remitiendo a la relación existente entre ese lugar y una simbología cultual/funeraria que se traspasa de generación en generación.

El estudio, que tuvo como objetivo principal la realización de un análisis general del mundo funerario romano gallego tanto cuantitativa como socialmente, se centró en la revisión de 48 casos (Tabla 1). Con ellos se trató de observar distintos aspectos como su distribución, ritual funerario, tipología, orientación, restos óseos y materiales asociados, poblaciones vinculadas a las necrópolis y relación con su entorno. Para ello se recurrió a la creación de una base de datos con las que obtener fichas individualizadas divididas en cinco grandes bloques:

1. Datos relativos al ámbito topográfico y toponímico.

2. Información referente a la sepultura: actuaciones arqueológicas (incluyendo año, dirección y motivo, siempre que sea posible), tipología, número de individuos y el tipo de ritual realizado (inhumación, cremación o ambas), orientación, restos 
óseos (y en caso de que hubiese, especificar cuáles), ajuar (igual que en el caso anterior), otros restos (misma idea que los dos anteriores y referido, principalmente, a restos del ataúd y todo aquello que no perteneciese a los dos casos precedentes).

3. Relaciones con el paisaje: monumento funerario asociado y yacimientos próximos coetáneos.

4. Cronología (inicialmente con una subdivisión en altoimperial, tardorromana o uso durante todo el Imperio; aunque incluyendo una datación más concreta cuando así se pudiera), grado de certeza (alto, medio o bajo²) y bibliografía.

5. Apartado gráfico, siempre que fuera posible.

La información que completa cada ficha individualizada consistió en el resultado de una combinación de datos bibliográficos y aquellos procedentes de las fichas y memorias de intervención presentes en el Servizo de Arqueoloxía da Consellería de Cultura, Educación e Ordenación Universitaria da Xunta.

Tabla 1. Relación de yacimientos estudiados.

\begin{tabular}{|c|c|c|c|c|}
\hline Registro & Topónimo & Concello & Ritual & Cronología \\
\hline GAR15031002 & A Hermida & Culleredo & 1 & IV \\
\hline GA15024001 & Agra de Guisande & Cerceda & I & Fins IV-VII \\
\hline GA15024REF-5 & Coto do Regueiro/Agras de Campomaior & Cerceda & 1 & TR \\
\hline GA15030007 & Calle Real con Riego de Agua & A Coruña & $\mathrm{I} / \mathrm{C}$ & I/II-III/IV \\
\hline GA15030007 & Calle Agar & A Coruña & I & TR \\
\hline GA15072124 & $\mathrm{n}^{0} 9$ y 10 de la Plaza Rafael Dieste & Rianxo & $\mathrm{I} / \mathrm{C}$ & II- VI/VII \\
\hline GA15080ACH005-008 & A Areosa & Sobrado dos Monxes & C & Fins II- $1^{0} \quad \frac{1}{2}$ III d.C \\
\hline GA27028164 & Recatelo & Lugo & 1 & TR \\
\hline GA27028164 & Campo da Feira/ A Mosqueira & Lugo & I & IV \\
\hline GA27028164 & Plaza da Constitución & Lugo & $\mathrm{I} / \mathrm{C}$ & IV \\
\hline GA27028164 & Calle San Roque n³1-33 & Lugo & $\mathrm{I} / \mathrm{C}$ & Hasta V \\
\hline GA27028164 & Plaza de Ferrol & Lugo & C & I-2 $1 / 2$ III d.C. \\
\hline GA27028164 & Campo da Forca I y II & Lugo & C & $\mathrm{Al}$ \\
\hline GA27028164 & Ronda da Muralla $n^{0} 7$ y 8 & Lugo & 1 & fins III- pp. IV d.C. \\
\hline GA27019010 & Fazouro & Foz & 1 & TR \\
\hline GA27024002 & Belesar & O Incio & I & TR \\
\hline GA27024007 & O Modorro de San Pedro & O Incio & I & TR \\
\hline GA32090001 & Parada de Outeiro & Vilar de Santos & 1 & fins III-IV d.C. \\
\hline GA32054002 & As Burgas & Ourense & 1 & TR \\
\hline Sin localizar & A Costa & Verín & & \\
\hline GA32028010 & O Castelo & Cualedro & & \\
\hline GA32091REF-3 & Trasiglesia & Vilardevós & 1 & \\
\hline GA36057035 & Illa de Toralla & Vigo & I & TR \\
\hline GA36051011 & A Lanzada & Noalla & $\mathrm{I} / \mathrm{C}$ & TR \\
\hline GA36057085 & Picacho-San Francisco & Vigo & 1 & TR \\
\hline GA36057083 & O Areal/El Arenal/Calle Hospital n5 & Vigo & $\mathrm{I} / \mathrm{C}$ & $\mathrm{I}-\mathrm{XIII} / \mathrm{XV}$ \\
\hline GA36057083 & Rosalía de Castro II & Vigo & I & III-IV \\
\hline GA36057086 & Casa Mar & Vigo & & \\
\hline
\end{tabular}

2 Valoración personal de la información basándose en si existen abundantes referencias de la necrópolis y, por lo tanto, posibilidad de contrastación de la misma. 


\begin{tabular}{|l|l|l|l|l|}
\hline GA36022004 & Adro Vello & O Grove & I & $\begin{array}{l}\text { IV/V-VII d.C. hasta } \\
\text { el siǵlo XVIII }\end{array}$ \\
\hline GA36051024 & Pardillo & Sanxenxo & I & TR \\
\hline Sin Localizar & Bermes & Lalín & & \\
\hline Sin localizar & Urgal & Belesar/Baiona & & \\
\hline GA36045001 & O Pazo & Redondela & I & TR \\
\hline GA36901003 & Punta Riasón & Illa de Arousa & I & \\
\hline GA36060014 & Arealonǵa & Villagarcía & I & IV/V-X d.C. \\
\hline GA36055035 & Santo Domingo y Loureiro & Tui & I & TR \\
\hline GA15041REF-001 & A Medoña & Laracha & I & $2^{0}$ 1/2 IV-V d.C. \\
\hline GA15086018 & A Iǵlesia/Tras Iglesario & Trazo & I & \\
\hline GA36054019 & Currás & Tomiño & I & VI \\
\hline GA32085020 & Centro histórico & Verín & & I-III \\
\hline GA15065001 & Iria Flavia & Padrón & & Todo el Imperio \\
\hline GA15078030 & Catedral & Santiago de Compostela & I & III-IV/V d.C. \\
\hline Sin localizar & Padrón & Redondela & & \\
\hline GA36056007 & Martores & Valga & I & TR \\
\hline GA27041017 & Castillóns/Castillós & Pantón & I & IV \\
\hline GA36022001 & Punta de Cantodorxo & O Grove & I & \\
\hline GA36055047 & Subida do Anxo & Tui & I & \\
\hline GA15030007 & Calle de la Franja, 14/Casa Martelo & A Coruña & TR \\
\hline
\end{tabular}

I-Inhumación / C-Cremación / TR-Tardorromana / Al-Altoimperial

Posteriormente, y a partir de las localizaciones de cada una de las necrópolis, se trazó un mapa de distribución con el que pudimos analizar las zonas de mayor presencia y, por tanto, de mayor proximidad a núcleos de población (ya sean civitates, villae, vici...).

\section{Resultados Y Discusión 3}

\subsection{Distribución (Fig.1)}

Tras un primer análisis se detectó una mayor presencia en la provincia de Pontevedra con unas 19 necrópolis registradas y, en su mayor parte, concentradas en la costa (p.ej. la ciudad de Vigo cuenta con 5 necrópolis, estando 4 de ellas en el propio centro urbano -Picacho, O Areal, Rosalía de Castro II y Casa Mar-). En el caso de las provincias restantes el número se reduce a 12 para el caso de A Coruña, 11 en Lugo (concentrando 7 de ellas en el casco histórico de la antigua Lucus) y 6 en Ourense.

Esta alta tasa de concentración en la costa pontevedresa se observa también en el trabajo de Valle Abad sobre necrópolis romanas costeras en Galicia donde alcanza el $72.2 \%$ del total. El resto de necrópolis estudiadas se distribuyen entre el Frente Ortegal-Fisterra

3 Los resultados que se muestran a continuación tienen su origen en el Trabajo Final de Máster llevado a cabo por la propia autora en 2015 bajo la dirección de los doctores Rosario Cebrián Fernández y Felipe Criado-Boado. Es importante matizar que en aquel momento la metodología empleada no fue todo lo exhaustiva que hubiésemos deseado al no poder contar con tiempo y medios suficientes. A pesar de ello, consideramos que los datos obtenido son de interés y permiten realizar una pequeña aproximación al mundo funerario en la Galicia de los siglos I a. C.-VI d. C. Actualmente dicho proyecto ha supuesto la base para la tesis que se está desarrollando con el fin de poder entender el proceso de cambio, tanto tipológico como mental, que se produce a lo largo de los siglos IV-X d. C. para el mismo espacio geográfico. 
(16.6\%), la Fachada Cantábrica y el Frente Baiona-Porto (ambos con 5.6\% respectivamente) (VALLE ABAD 2017:300)

Dicha acumulación de restos funerarios en áreas costeras respondería probablemente a una óptica económica. Estas zonas no son solo producto de la actividad directamente relacionada con la explotación de los recursos marinos, sino que son también espacios de tierras fértiles para la agricultura; estando al mismo tiempo comunicada con redes de transporte y comercio marítimo, así como con una serie de núcleos secundarios, que en este momento se refuerzan en su cometido de articuladores del desarrollo rural. (CARLSSON-BRANDT 2011b: 162-163; PÉREZ LOSADA 2002)

Al mismo tiempo no debemos apartar de esta explicación el condicionante que se mencionaba sobre una constante realización de campañas arqueológicas con carácter de urgencia y sobre suelo urbano. La costa suroeste gallega ha sido, y sigue siendo, un espacio de fuerte desarrollo en las investigaciones arqueológicas, así como un área ampliamente afectada por la presencia humana desde sus orígenes. La búsqueda de nuevas informaciones y las continuas obras urbanísticas han permitido sacar a la luz el pasado histórico de determinadas ciudades, pero esto no debe hacernos caer en el error de pensar que otras áreas internas/rurales no poseen una potencia similar de yacimientos funerarios.

Figura 1. Distribución de los yacimientos funerarios Fuente propia.

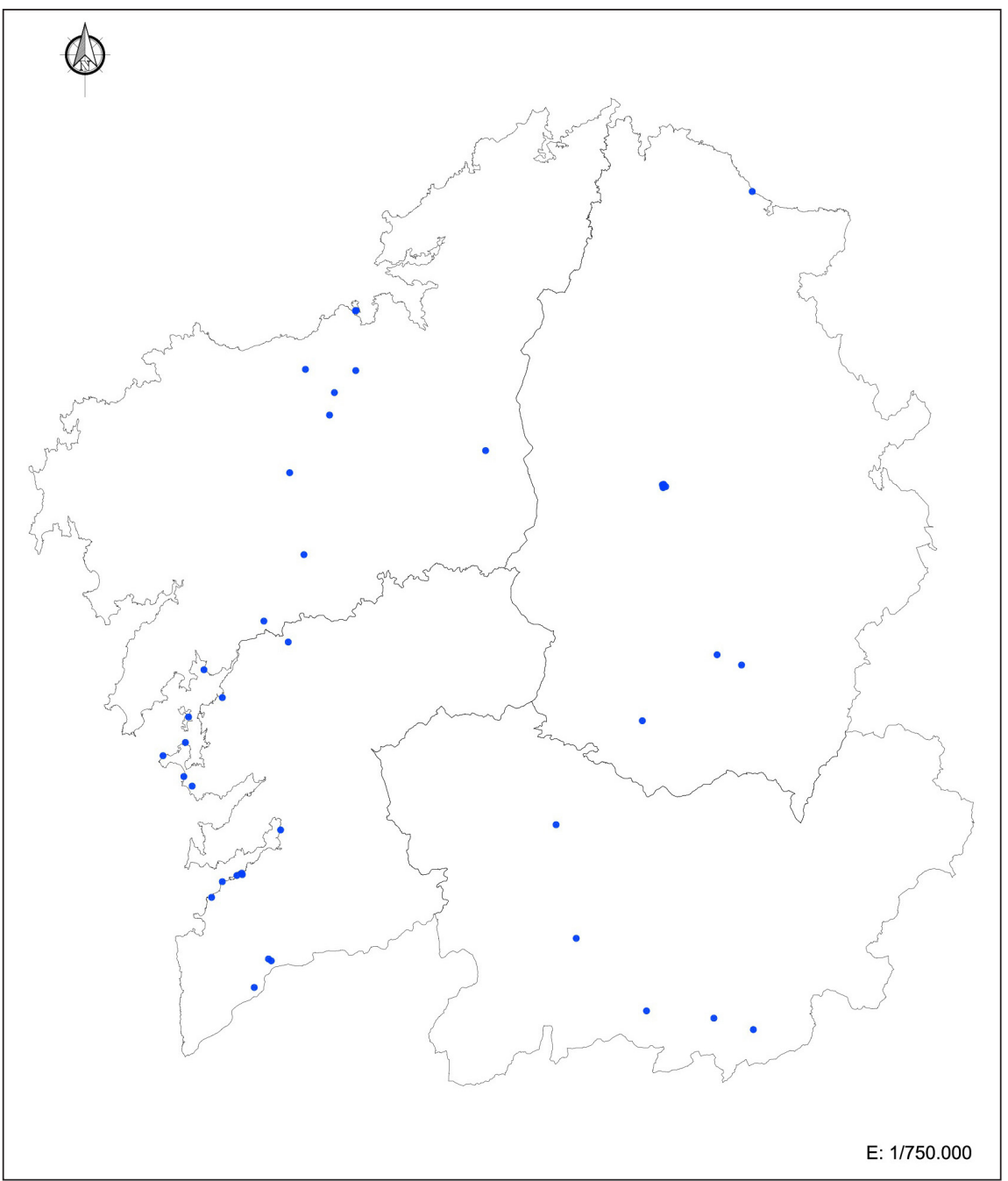




\subsection{Ritual funerario}

Tradicionalmente y desde un punto de vista general se ha marcado un límite en la segunda mitad del siglo II-inicios del III d. C. como el momento en el que se produce el salto de un ritual crematorio a uno inhumatorio (VAQUERIZO GIL 2007: 142). Aunque efectivamente dicho cambio se realizó en estas fechas, la coexistencia de ambos rituales fue constante a lo largo de este período de cambios y en la mayor parte de los casos el uso de uno u otro rito dependía de la posición económica, social, religiosa y de elección del propio inhumado. A partir del siglo III d. C. el uso de la inhumación fue cada vez mayor hasta generalizarse por completo en los siglos IV/V d. C. (SEVILLA CONDE 2014; VAQUERIZO GIL 2007, 2011b)

Para el caso gallego se ha observado un alto número de necrópolis de inhumación frente a las de cremación o aquellas que aúnan ambos ritos, situándose estas últimas en enclaves como Coruña, Vigo, Lugo o La Lanzada. Este fenómeno nos estaría indicando la reutilización de este espacio a lo largo de todo el Imperio y, por tanto, nos habla de una sociedad que mantiene la sacralidad de ese lugar a pesar de los cambios religioso que se están produciendo. La mayor parte de estas necrópolis de inhumación pertenecían al ámbito cronológico de la tardoantigüedad, momento en que las capitales de los distintos conventus son promovidas a obispados (s.IV d. C.) se generaliza la construcción de espacios cultuales (s. V-1 $\mathrm{a}_{1} / 2$ VI d. C.) y surgen martyria y complejos funerarios (s. IV/V d. C.) (LÓPEZ QUIROGA, BANGO GARCÍA 2005: 30-31)

\subsection{Tipología (Fig.2)}

Para este apartado, y tras encontrar diferentes formas de definir ambiguamente un mismo tipo de enterramiento y no poder concretar en determinados casos a qué tipo de tumbas se hacía referencia, se hizo necesario crear una tipología propia que atendiese a la estructura y material de los mismo, permitiendo que fuese fácilmente utilizada en todos los yacimientos. Resultado de ello son estas 5 adscripciones:

a) Fosa tallada en la roca

b) Fosa delimitada por tegulae (con tégulas hincadas en la tierra creando una estructura en planta cuadrada o rectangular y sección rectangular o triangular -tumba capuccina-)

c) Fosa delimitada por lajas de piedra (siguiendo el mismo esquema que en el caso anterior)

d) Fosa excavada en terreno natural (cuando no existe una estructura definida salvo el mero espacio en el suelo)

e) Sarcófago (generalmente exentos y aquellos con cubierta de granito y estructura monolítica) 


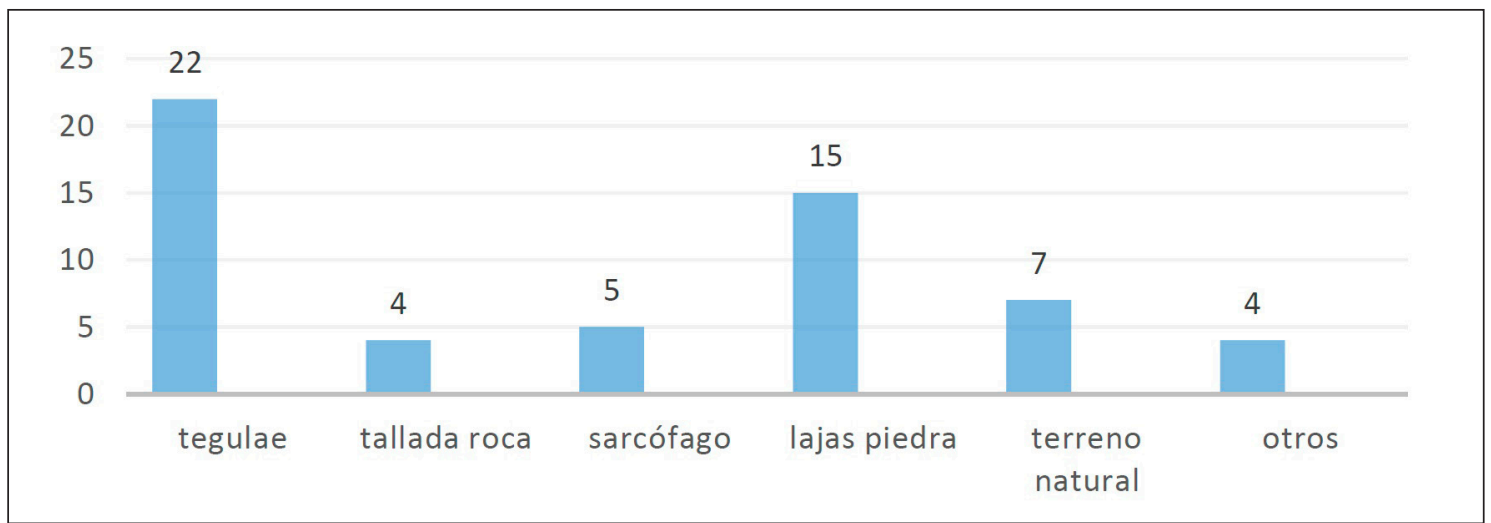

Figura 2. Tipología de enterramientos. Fuente propia.

Dejando a un margen las urnas de cremación, que en los casos estudiados se realizan en material cerámico y se encuentran dentro de estructuras cuadrangulares en tegulae o en fosas realizadas en el propio terreno natural (A Areosa, Sobrado dos Monxes ${ }^{4}$, Plaza de Ferrol5 ${ }^{5}$, Lugo y Campo da Forca I y II ${ }^{6}$, Lugo. Fig.3), se observa que las estructuras de inhumación destacan por un uso principal de tegulae y/o piedra (Fig.4). Para este último caso se observa un empleo continuado de materiales locales como el granito y la pizarra (aunque más escasa, es la más utilizada por su facilidad para ser transportada en losetas y su superior resistencia a la erosión). En yacimientos como O Pazo (Redondela), Arealonga (Villagarcía) o Illa de Toralla (Vigo) el empleo de la tégula y la piedra se mezclan para crear estructuras funerarias con material mixto (Fig. 5).

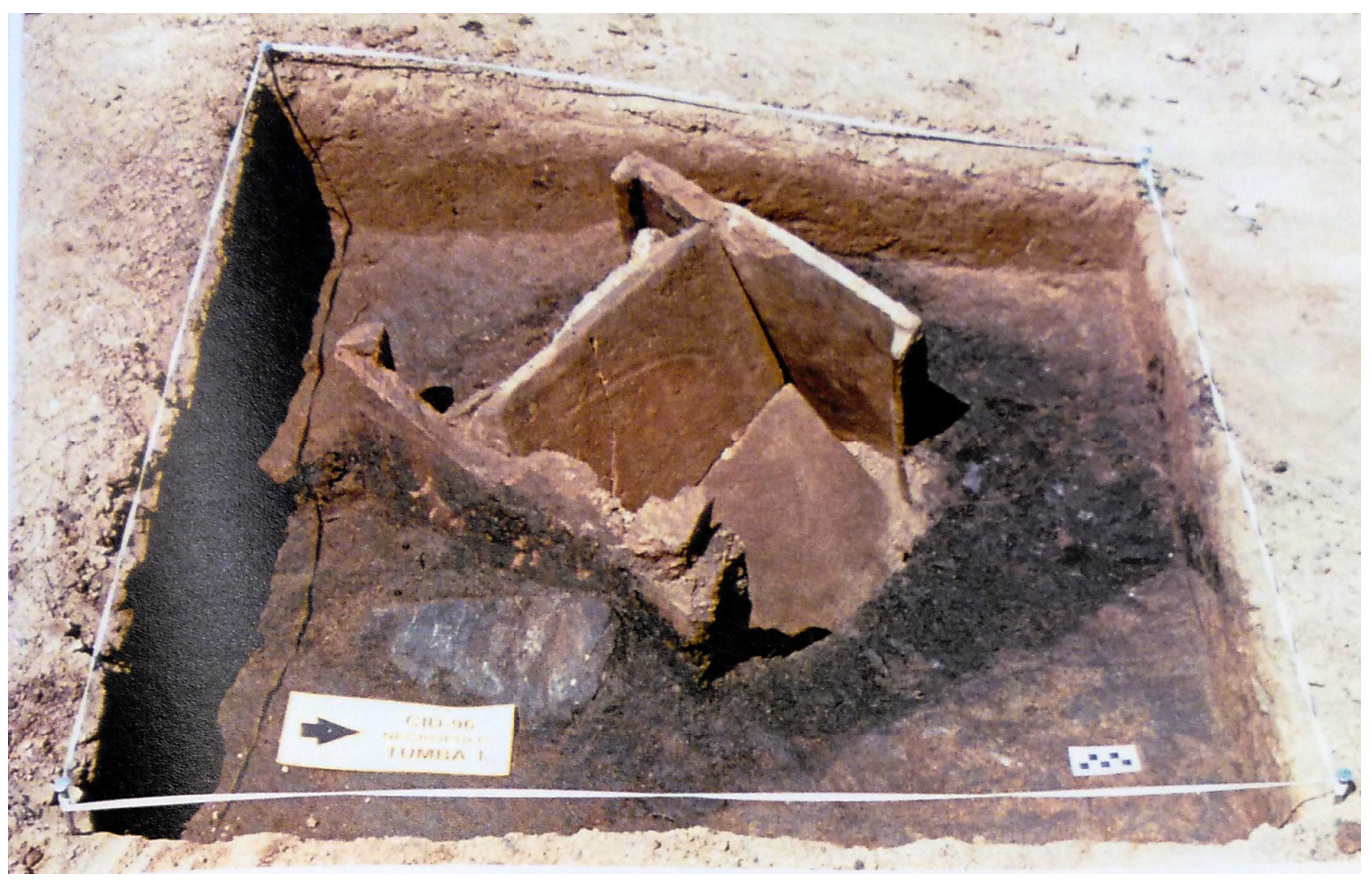

Figura 3. A Areosa (Sobrado dos Monxes -CO007-). Fuente: Servizo de Arqueoloxía. Xunta de Galicia.

(CAAMAÑO GESTO, FERNÁNDEZ RODRÍGUEZ 2002)

(RODRÍGUEZ COLMENERO, CARREÑO GASCÓN 1987)

6 (CARREÑO GASCÓN 1989) 


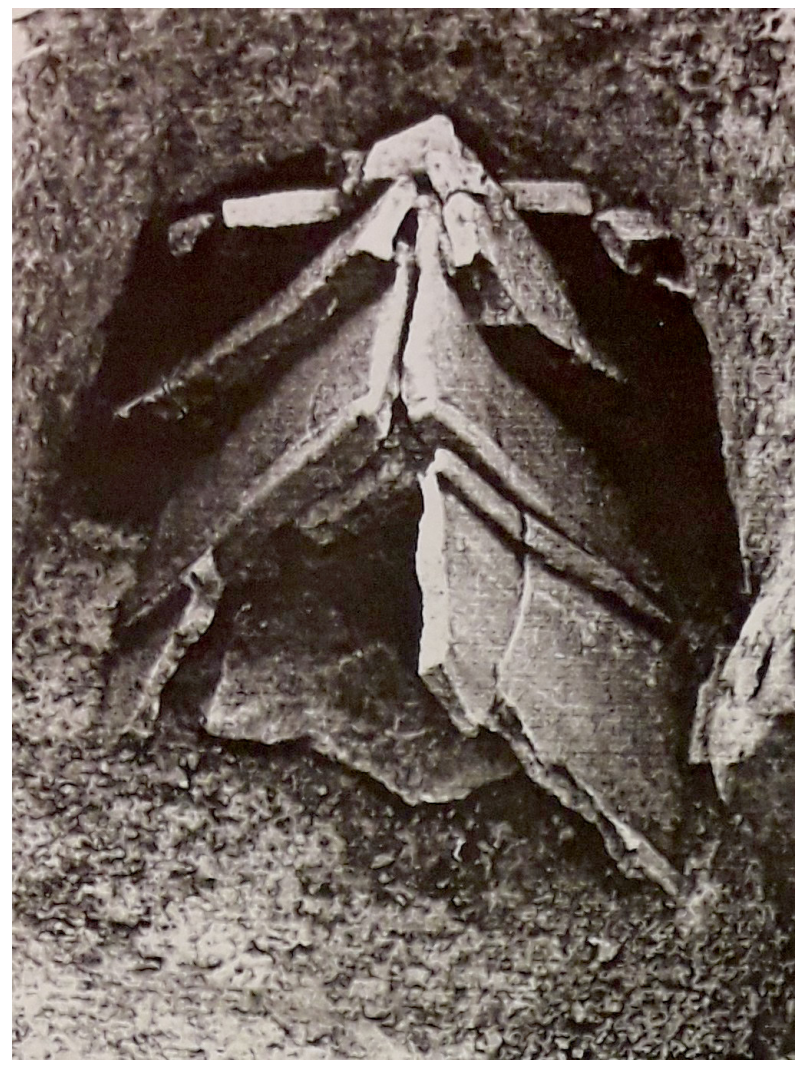

Figura 4. Sepulcro realizado en tegulae en la necrópole de Loureiros (Rebordáns, Tui -PO014-). Fuente: Servizo de Arqueoloxía. Xunta de Galicia.

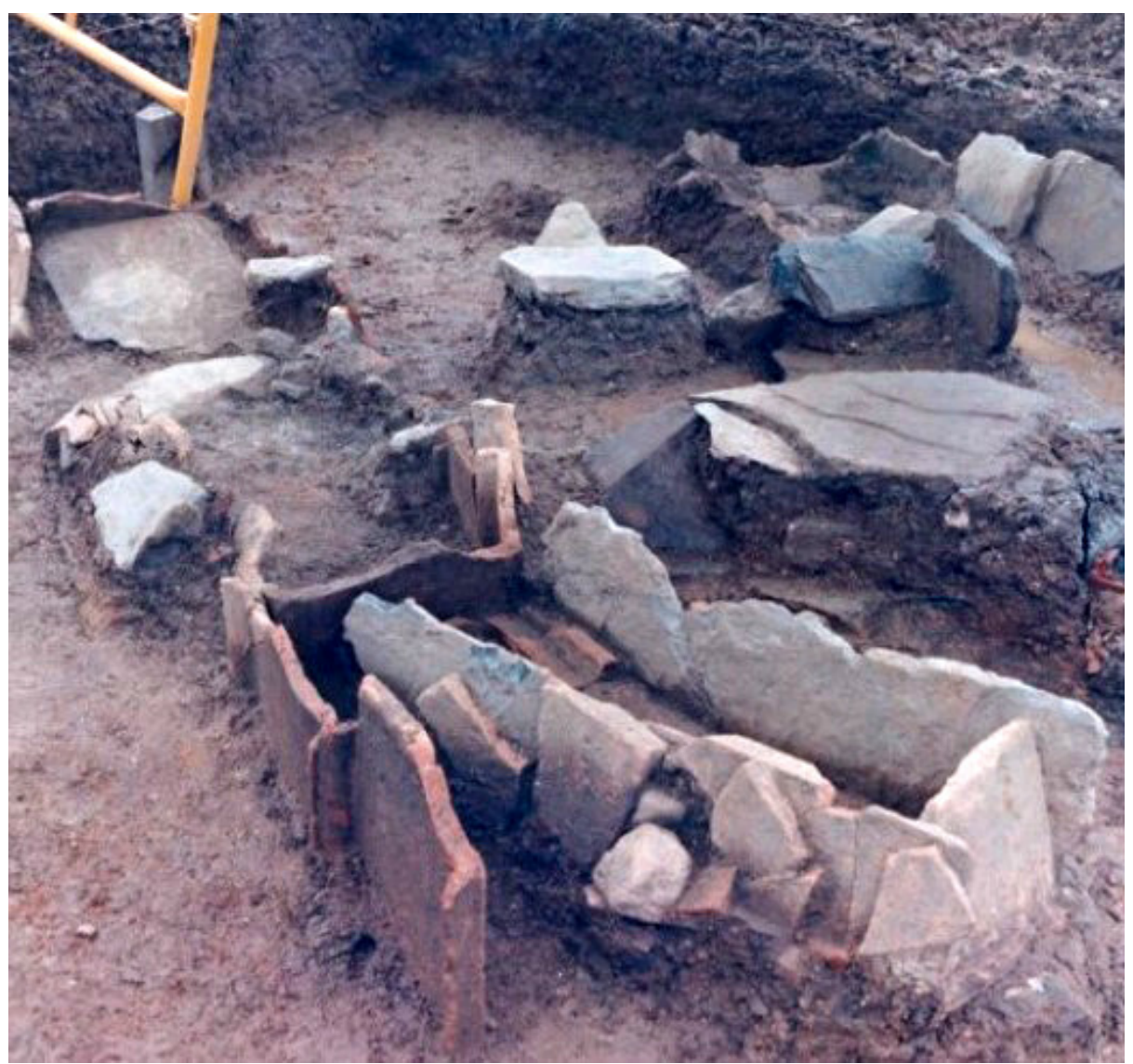

Figura 5. Sepulcro mixto (tegulae y piedra) en la necrópolis de la Plaza de la Constitución (Lugo -LU003-). Fuente: Servizo de Arqueoloxía. Xunta de Galicia. 
La existencia de un número elevado de estructuras con tégulas hincadas o, en su defecto, mezclada con piedra local, está reflejando una sociedad ampliamente romanizada que incorpora una tradición importada como es la tégula en los enterramientos. Sin embargo, es una población que utiliza al mismo tiempo un material local de menor coste que el anterior. Esto nos hace pensar si el uso de uno u otro tipo estaría vinculado al nivel económico de cada familia, sin dejar de lado las variaciones locales, modas, etc., de tal manera que aquellas con un alto poder adquisitivo buscarían ser representadas al modo romano (fosa delimitada por tegulae), mientras que otras con un nivel menor solo podrían alcanzar a pagar el coste de un enterramiento con materiales locales.

El uso de tégulas como en A Areosa (Sobrado dos Monxes), A Lanzada (Noalla), Pardillo (Sanxenxo) y Santo Domingo y Loureiro (Tui), han permitido que lleguen hasta nuestros días improntas de los constructores de las tumbas a través de digitalizaciones con formas curvas, símbolos cristianos (únicamente en A Lanzada) y figuras concéntricas (Fig.6).

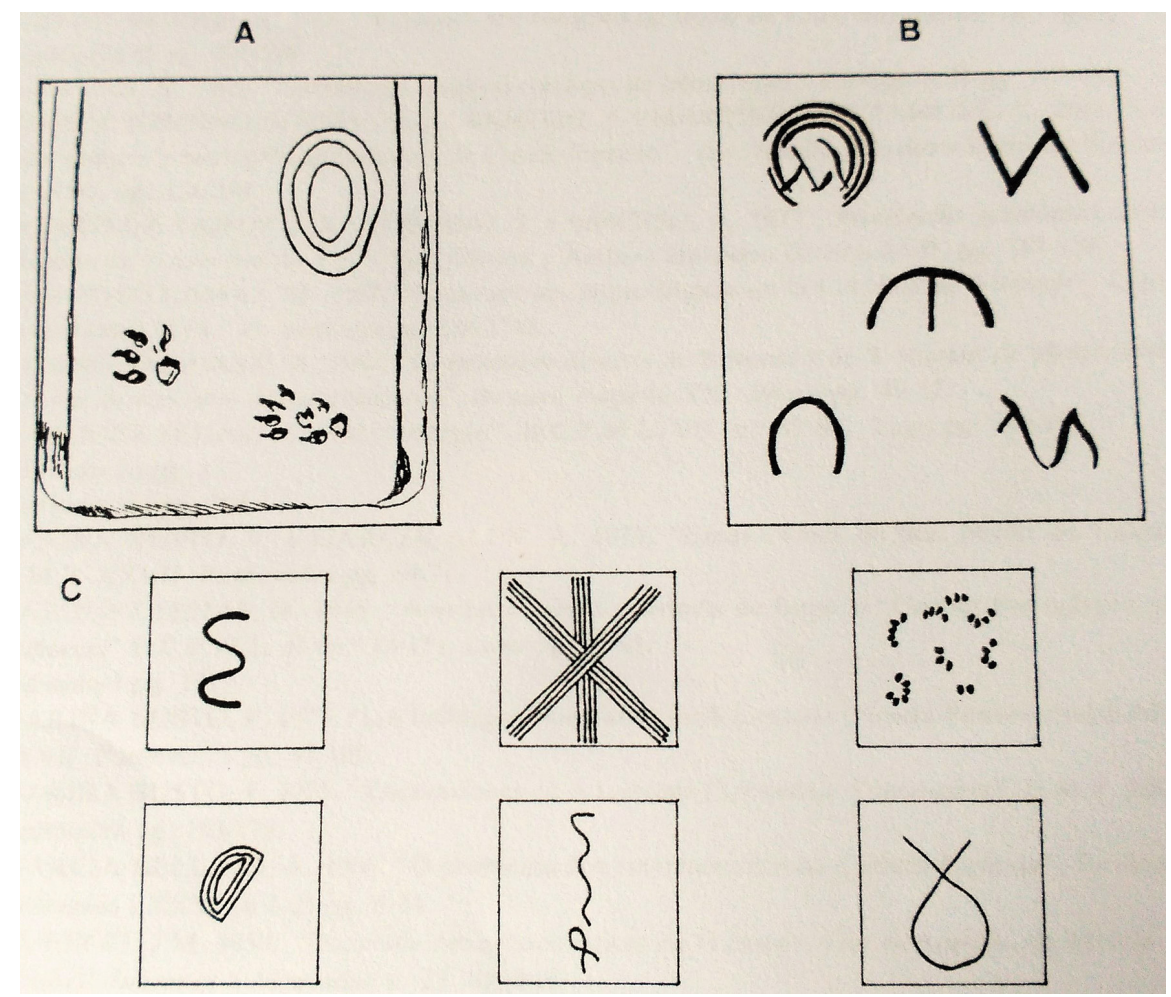

Figura 6. Tégulas con marcas. Fuente: González Fernández, 1987, 223.

En menor proporción, hallamos sarcófagos exentos y excavados en la roca ${ }^{7}$ donde la cronología nos muestra un tiempo a caballo entre el final de la tardorromanidad y el Medievo. Casos como Agra de Guisande (Cerceda), Adro Vello (O Grove) u O Areal, se corresponden con necrópolis cuyo uso se extiende hasta el siglo VI-VII d. C. (en el caso de Adro Vello incluso hasta época moderna), siendo influenciados por la presencia en esos momentos del cristianismo.

7 Dos tipos de enterramientos que son objeto de un estudio más exhaustivo en el proyecto actual de tesis. 
La nueva religión seguirá manteniendo la idea que se mencionaba al inicio de visibilización social de la muerte, por lo que optarán por estructuras funerarias que represente poder y lujo. Las tipologías relacionadas principalmente con el cristianismo son el sarcófago monolítico y el tallado en la roca, siendo utilizado el primer tipo en el siglo II d. C. como influencia oriental y vinculada a la élite romana. En este período la élite eclesiástica retomará dicha tradición como signo de poder. (AVIAL-CHICHARRO, BLANCO TORREJÓN 2017:481)

$\mathrm{Al}$ igual que ocurría en el caso del ritual funerario, los tipos de enterramiento no son cajas independientes, sino que convivirán simultáneamente en el tiempo generando necrópolis con variedades tipológicas y cronológicas. Por ejemplo, en O Areal coexisten un total de cinco tipos diferentes (fosa excavada en terreno natural, delimitada por tegulae, por lajas de piedra, mezcla de ambas y tallada en la roca) que nos indican la elección por parte del fallecido, familia y/o grupo social al que pertenece y el uso del mismo espacio a lo largo de todo el Imperio.

\subsection{Orientación}

Determinar la orientación de una tumba no está exento de problemas, pues en muchos casos o no es posible acceder al yacimiento, no está referenciada correctamente, se están tomando como puntos otras partes de la tumba que se desconocen o la orientación está determinada por un elemento exógeno a la propia tumba. Debido a ello contamos con un número reducido de necrópolis en las que se observa 18 veces la orientación E-W; 3, N-S (Calle San Roque -Lugo-, A Lanzada -Noalla- y Rosalía de Castro II -Vigo-) y 2, NW-SW (O Areal -Vigo- y Rosalía de Castro II).

La orientación E-W responde, simbólicamente, al curso que realiza el Sol a lo largo del año pero, como apoya el investigador López Borgoñoz (1999), esto no significa que el deseo del inhumando sea encararse con el Sol naciente más que con el Sol poniente. Un Sol naciente que no se vería reflejado por su posición exacta en el momento de la inhumación, sino por aquella considerada como tradicional y utilizada por la gran mayoría. (SEVILLA CONDE 2014: 204)

La segunda orientación predominante, $\mathrm{N}-\mathrm{S}$, coincide con aquellas inhumaciones localizadas en necrópolis cuyo uso se extiende a lo largo del Imperio, o lo que es lo mismo, forman parte de ese primer núcleo inicial de enterramientos no crematorios. En zonas como la Gallia este uso está vinculado a la pervivencia de una tradición celta, algo que aquí se puede defender con el uso de esta misma orientación en los túmulos megalíticos ${ }^{8}$.

Una vez que entra en juego el cristianismo, la orientación habitual pasa a ser W-E y podría enraizarse con la pervivencia del Sol como hito de referencia y, al mismo tiempo, con la orientación hacia Jerusalén y la supuesta llegada del Mesías por el este. (SEVILLA

8 Dichas mámoas se encontrarían dentro de una red de túmulos cuya orientación principal es N-S y unas relaciones entre los cuatro cuadrantes que suelen producir una simetría directa entre la mitad septentrional y la meridional y dan lugar a una simetría inversa entre la oriental y la occidental. Mientras el lado del oriente está pegáado a la vida (luz), el del occidente parece vincularse al mundo silvestre (muerte) (CRIADO BOADO 2013: 15). Dicho complejo de mámoas nos está indicando una clara intencionalidad de mostrar y recordar al fallecido. 
CONDE 2014: 205). En nuestro caso no se ha hallado ningún yacimiento con una orientación de este tipo, aunque, retomando los problemas que rodean a este apartado, podría ocurrir que alguna de las registradas como E-W fueran realmente W-E.

A partir de los siglos V/VI d. C., y relacionado con las tipologías de sarcófagos exentos monolíticos y tumbas excavadas en roca, se empiezan a observar unos cambios en la orientación de las tumbas. Aunque principalmente se sigue manteniendo la orientación cristiana W-E, se encuentran tumbas cuya orientación está determinada por la inclinación del terreno, el muro de la iglesia u otros elementos característicos en el paisaje (GONZÁLEZ GARCÍA 2016). De nuevo nos hallamos ante una orientación determinada por el espacio, más allá del carácter simbólico, como ocurría en época altoimperial (disposición de las tumbas próximas a vías de comunicación -Gräberstraßen-, murallas, cursos fluviales, etc.)

\subsection{Restos óseos y materiales asociados}

Finalizando el análisis interno de las necrópolis, es importante realizar un breve acercamiento a los restos óseos y materiales que se han hallado en ellas. Cuantitativamente tenemos 17 yacimientos con restos óseos, 21 con restos de ajuar y 18 enclaves en los que se han hallado algún resto perteneciente al ataúd de madera u otros elementos (Fig.7).

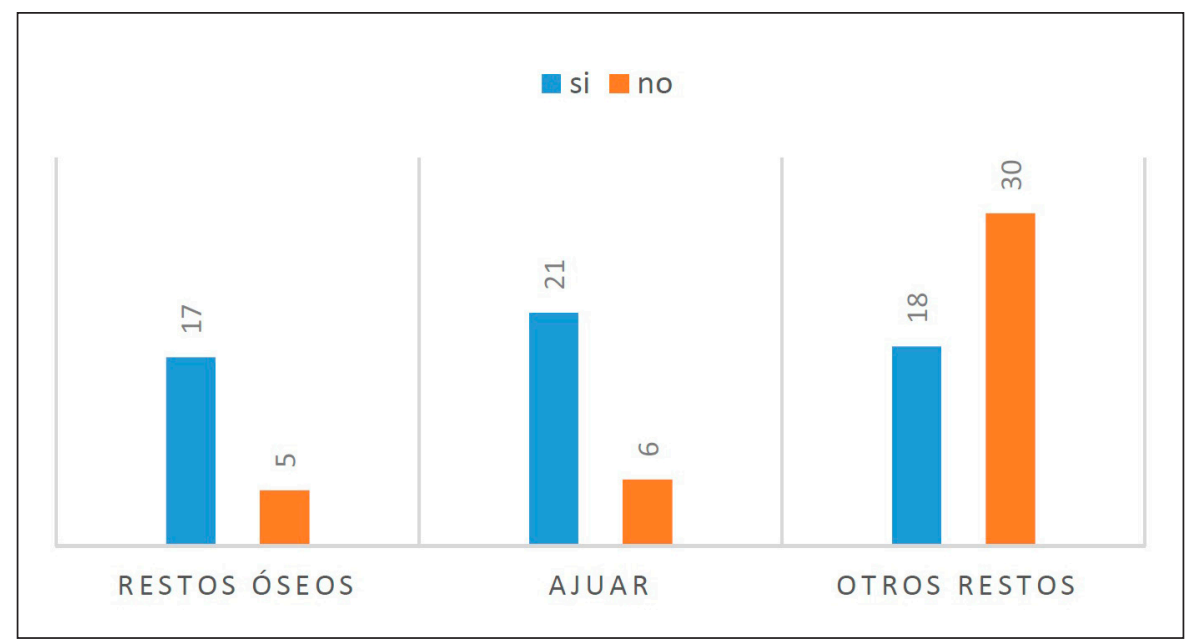

Figura 7. Restos materiales presentes en las necrópolis. Fuente propia.

Si se compara con el número total de necrópolis halladas, la cifra es claramente muy inferior. En parte dicha ausencia se debe a una acidez propia del suelo gallego, algo que afecta en gran medida a todos los restos inorgánicos como huesos, causando la buena preservación de los orgánicos como madera y carbón; expolios varios que hayan podido sufrir estos espacios y la propia intencionalidad del difunto.

Con respecto a los restos óseos, hemos observado la existencia de una abundancia de huesos largos, fragmentos de ambos maxilares (habitualmente el inferior por tener un mayor componente óseos) y cráneo y esquirlas óseas procedentes de cremaciones. Quizás entre los ejemplos más destacables se halla el cuerpo completo de una mujer joven 
que conservaba aún en el interior de la pelvis su hijo nonato, ambos cubiertos por piedras y conchas (tumba 30 de A Lanzada, Noalla) (BLANCO FREIJEIRO, et al. 1967:20).

En la mayor parte de los casos, junto al cuerpo o las cenizas del difunto se encuentra un conjunto de objetos que acompañaban a este al otro mundo. Artefactos, alimentos, monedas... depositados en tumbas desde época prehistórica y que continúan en esta basándose en la creencia de la existencia de un más allá en el que el fallecido debía estar junto aquellas cosas que lo identificaban y que podría necesitar en esa nueva andadura.

En el caso de La Lanzada se han hallado, ente los pocos ajuares asociados a fallecidos, diferentes vasos cerámicos, objetos de vidrio, alfileres de hueso y bronce para el pelo y ropa, tachuelas de hierro del calzado, monedas, conchas de diferentes moluscos (principalmente vieiras, berberechos y almejas) e imbrices para elevar el cráneo del difunto una vez que estuviese en posición decúbito supino (una elevación del cráneo que se considera casi única en la Península, pues solo encuentra similitudes en las necrópolis lusitanas y el Midi francés (BLANCO FREIJEIRO, et al. 1961:152).

En el caso de los cinco yacimientos en los que se especifica la no existencia de un ajuar asociado puede estar indicándonos, si dejamos de lado la posibilidad de un expolio, la presencia de un ritual inhumatorio de tradición cristiana. Recordemos que en esta religión existe la idea de austeridad y de "ser iguales ante la muerte" que tiene su reflejo inmediato en la reducción de los elementos que conformaría el ajuar. Mención aparte serían las tumbas visigodas donde se solía enterrar al fallecido con ricos y amplios bienes.

A lo largo de época tardoantigua se convierte en una constante la reutilización de los enterramientos y los restos del anterior fallecido, son desplazados a los pies de la tumba (FARIÑA BUSTO, SUÁREZ OTERO 1997: 311) tal y como se ve en la necrópolis de O Areal (Vigo) donde uno de los esqueletos completos apoya su cabeza en un segundo cráneo procedente de otro enterramiento anterior cuyos restos son desplazados a los pies del primero (CONSTELA DOCE 2008, GONZÁLEZ FERNÁNDEZ 1985/86).

Por último, la mayor parte de los restos encontrados no vinculados al ajuar son piezas de metal, restos de cremaciones, clavos de hierro, abrazaderas laterales, madera carbonizada o un sistema de libaciones en Ronda da Muralla, Lugo. Con este tipo de restos materiales queda constatado el empleo de ataúdes de madera, especialmente en aquellas tumbas que carecen de una estructura sólidas definida.

\subsection{Relación con su entorno}

Finalmente, y como se comentaba al inicio de este artículo, la arqueología funeraria dibuja un paisaje de tres esferas siendo una de ellas los núcleos de población (civitates, vici, villae...) próximos a las zonas de enterramientos.

Se ha constatado la existencia de relaciones directas en el entorno con castros, civitates y, en menor medida, villae. En concreto tenemos 7 yacimientos asociados a villas, 15 a civitates y/o asentamientos portuarios, 10 a castros y 3 más asociados a un campamento (A Areosa, Sobrado dos Monxes relacionado con el fuerte romano de A Cidadela), un posible templo o santuario (Plaza Rafael Dieste, Rianxo) y un vicus (A Areosa se encuentra al mismo tiempo muy próxima del antiguo vicus de Insua). 
En las necrópolis de Illa de Toralla (Vigo), Adro Vello (O Grove), Arealonga (Villagarcía), Currás (Tomiño) y Castillóns (Pantón) se observa una relación doble con una vinculación simultánea a una villa y a un castro. De esta forma se dibuja en el paisaje una evolución habitacional que permitiría hacer una lectura temporal que arranca en la Edad del Hierro, donde las poblaciones habitarían en los oppida, y cuyo paisaje es transformado posteriormente con la fundación de la villa y cementerio (CARLSSON-BRANDT FONTÁN, FERNÁNDEZ ABELLA 2014:231)

Relacionado con estos dos últimos elementos, en aquellos casos en los que la necrópolis se asienta próxima a una villa (CHAVARRÍA ARNAU 2007), esta lo hace en una zona exógena al área habitacional (siempre dentro de los límites del fundus), dotada de protección natural y próxima a una vía de comunicación (p.ej. en la Calle San Roque, Lugo se descubre una vía de orientación N-S que delimita la necrópolis por el E; o en la Plaza de Ferrol, también en Lugo, la necrópolis delimita al NE con una calzada y restos de un acueducto). En ocasiones esta reconversión total o parcial de la villa en necrópolis precede a la creación de una iglesia o espacio cultual en ella (SÁNCHEZ PARDO 2012: 267); pero esto no significa que todas las necrópolis de los siglos V y VI supongan la creación automática de una iglesia, sino que este será un proceso que se extenderá hasta el siglo X y muchas veces estará vinculado a la presencia de un antiguo mausoleo (SÁNCHEZ PARDO 2013: 31).

\section{Algunos PRoblemas: INVISIBILIDAd y REPRESENTATIVIDAD DEL REGISTRO ARQUEOLÓGICO}

A la hora de interpretar en términos históricos los resultados obtenidos, es preciso tener en cuenta una serie de problemas que plantea el registro arqueológico. Tras la etapa prerromana cuya principal característica desde el punto de vista funerario es la invisibilización de la muerte, posiblemente vinculado al uso generalizado del ritual crematorio por parte de estas poblaciones tal y como afirmaba Tranoy (1981); el territorio galaico entró en una fase de clara oposición a la anterior y la muerte era y debía ser vista por toda la población. Sin embargo, como se ha visto, contamos con escasos datos de cementerios de cremación y la introducción de la inhumación remite a necrópolis con un número reducido de individuos (Fig. 8). De hecho, a partir del s.IV se observa una alta representación de enterramientos individuales totalmente aislados y sin ninguna relación directa con otro espacio funerario de mayor tamaño. Por tanto, se hace patente una infrarrepresentación de la sociedad que, al igual que ocurría en la epigrafía con estelas de élites locales que han absorbido un tria nomina, magistrados, militares, comerciantes...; solo nos permite aproximarnos a un núcleo minoritario y no representativo de toda la sociedad galaicorromana.

Quizás esta visión parcial nos está transmitiendo la existencia de otras prácticas que no han dejado restos tangibles, bien por el empleo de un ritual diferente o por el uso de materiales perecederos. Para este último caso podríamos mencionar la inhumación sin cajeado, que permitiría dejar al difunto en contacto directo con la tierra, vinculado a las 
creencias en seres naturales y el poder de esta como "Madre" de todas las cosas. Desde un punto de vista médico, tal y como nos explica el Benito López de Abajo (2005: 515), el proceso de putrefacción y coalicuativo puede durar de meses a años, finalizando en la esqueletización del cadáver; aunque este puede verse acelerado a causa del entorno al que esté expuesto (acidez del suelo, lluvia, ser alimento para animales...) provocando que no hayan llegado restos de estos cuerpos hasta nuestros días.

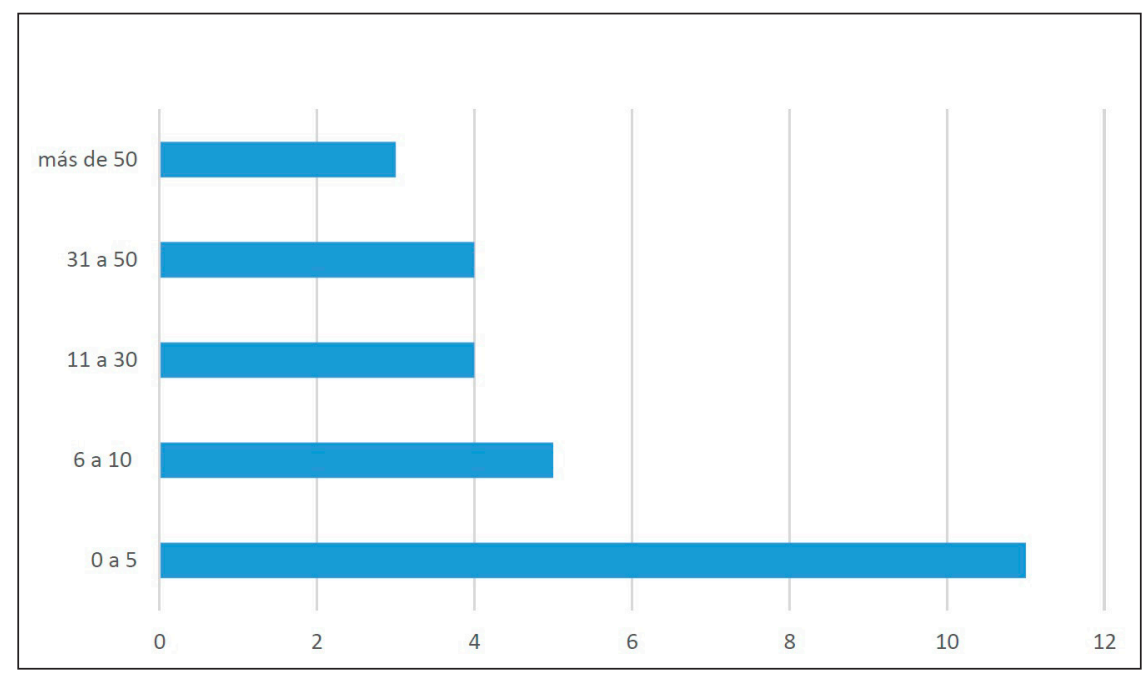

Figura 8. Número de tumbas dentro de las necrópolis. Fuente propia.

Por último, se ha observado una reutilización de los enterramientos (probablemente por parte de un mismo núcleo familiar), así como también de los asentamientos, a lo largo de este período (LÓPEZ QUIEROGA, LOVELLE 1999). Ejemplo de ello es el yacimiento de Adro Vello donde Carro Otero (1985/86) menciona que los datos coinciden con una población pequeña de aproximadamente 100 personas que se renovaría cada 2-3 veces por siglo. Tal vez sea esta superposición de cuerpos, la cual crea una superficie poliestratificada, una forma de perder restos del pasado.

\section{Conclusiones}

El objetivo principal de este estudio ha sido intentar en la media de lo posible obtener una primera visión general del mundo funerario romano en esta comunidad desde un punto de vista cuantitativo y social. En el primero de los casos se ha observado una gran variedad y amplio número de necrópolis de inhumación, sobre todo concentradas en áreas costeras y, principalmente en las Rías Baixas, pertenecientes en su gran mayoría al período tardoantiguo. Estamos ante un espacio muy dinámico desde el plano económico (CARLSSON-BRANDT 2011b) y donde las necrópolis se encuentran enmarcadas dentro de un entorno en el que destaca la presencia de villas/núcleos costeros y castros.

Para estas áreas funerarias sobresale la constante utilización de tumbas realizadas con tegulae y/o piedra local (granito y pizarra) que, posteriormente, son reutilizadas en algunos casos por otros individuos, como ocurre en el área tardoantigua de A Lanzada 
(LÓPEZ-COSTAS 2015). Dicha práctica, posiblemente por parte del mismo núcleo familiar, se manifiesta de igual forma en la reutilización del espacio cementerial a partir del siglo IV y hasta la segunda mitad del siglo VI (LÓPEZ QUIEROGA, LOVELLE 1999)

Por otro lado, la entrada del cristianismo supone un cambio sobre la concepción de la muerte la cual pasa a estar determinada no tanto por un miedo al olvido sino por un miedo a la muerte. Este sentimiento se ve reflejado en el aumento de tumbas depositadas cerca de emblemas de la cristiandad (enterramientos ad sanctos) que ayudarían en la salvación del alma del difunto y en en el ámbito tipológico donde se vira hacia estructuras monolíticas y excavadas en la roca.

Finalmente, esta investigación nos ha permitido observar numerosas áreas que todavía carecen de información o que presentan datos que precisan de revisión o actualización. En ese sentido es igualmente importante fomentar la divulgación de toda esta información e intensificar el trabajo de campo, realizar revisión completa de las fichas y memorias e intercambiar ideas con otros proyectos que se están realizando sobre el mundo rural romano en Galicia. Pero todo ello no servirá de nada si luego estos datos no son compartidos con el resto de la población.

\section{Bibliografía}

ARIAS VILAS, F. 1992. A romanización de Galicia. Vigo.

AVIAL-CHICHARRO, L.; BLANCO-TORREJÓN, L. 2017. «Contenedores funerarios. La concepción de la muerte en la Hispania Romana». En Actas de las II Jornadas de Jóvenes Investigadores en Arqueología. Madrid 21-23 febrero, 2017. Madrid. pp. 470-488.

AYÁN VILA, X.; LÓPEZ BARJA DE QUIROGA, P. 2007. "Una estela funeraria inédita de Taragoña (Rianxo, A Coruña)". Zeitschrift Für Papyrologie und Epigraphik, 161, 283-287.

AZKARATE GARAI-OLAUN, A. 2002. "De la Tardoantigüedad al Medievo cristiano: una mirada a los estudios arqueológicos sobre el mundo funerario". En D. Vaquerizo Gil (coord.), Espacios y usos funerarios en el occidente romano: actas del Congreso Internacional celebrado en la facultad de filosofia y letras de la universidad de Córdoba (5-9junio, 2001), Vol. II. Córdoba, pp. 115-140.

BARBEITO POSE, V.J. 2012. "Localización dunha necrópole mixta (inhumación, cremación) no casco antigo de Rianxo". Gallaecia, 31, 107-119.

BARROCA, M.J. 2010-11 "Sepulturas escavadas na rocha de entre Douro e Minho", Potugalia, 31-32, $115-182$

BLANCO FREIJEIRO, A. 1998. Arqueología gallega. Vigo.

BLANCO FREIJEIRO, A.; FUSTE ARA, M;, GARCÍA ALÉN, A. 1961. "La Necrópolis galaico-romana de La Lanzada (Noalla, Pontevedra)”, Cuadernos de Estudios Gallegos, XVI, 141-158.

BLANCO FREIJEIRO, A.; FUSTE ARA, M.; GARCÍA ALÉN, A. 1967. "La Necrópolis galaico-romana de La Lanzada (Noalla, Pontevedra), II”, Cuadernos de Estudios Gallegos, XXII, 5-23, 129-155.

CAAMAÑO GESTO, J.M.; FERNÁNDEZ RODRÍGUEZ, C. 2002. "Novedades sobre el campamento romano de Cidadela (Sobrado dos Monxes, A Coruña)", Gladius. Anejos 5, 213-226.

CARLSSON-BRANDT FONTÁN, E. 2011. "El poblamiento rural en la Galicia Romana. Un ejemplo: las villae. Metodología y problemática en su estudio", Estrat critic. Revista d’Arqueologia, 5, vol. 1, 156-167.

CARLSSON-BRANDT FONTÁN, E.; FERNÁNDEZ ABELLA, D. 2014. "La Ría de Arousa: un ejemplo de la ocupación y explotación de la costa en época romana", Arkeogazte, 4, 227-246.

CARREÑO GASCÓN, C. 1989. "Prospección arqueolóxica no 'Campo da Forca' (Lugo)", Campañas 1989. Arqueoloxía. Informes 3, Xunta de Galicia, pp. 65-69. 
CARRO OTERO, X.; MASA VÁZQUEZ, M.C.; VARELA OGANDO, Ma . L. 1987. "Un nuevo enterramiento de la necrópolis galaico-romana de La Lanzada (Noalla-Pontevedra)". Pontevedra Arqueológica, II, 229-252.

CARRO OTERO, J. 1965. Restos óseos antiguos de la provincia de Lugo. A Coruña.

CARRO OTERO, J. 1986. "Tres esqueletos de la necrópolis galaico-visigótica de San Xiao de Moraime (Muxía-La Coruña)", Cuaernos de estudios Gallegos, 36 nº101, 7-53

CARRO OTERO, J. 1996. "La necrópolis del yacimiento de Iria Flavia (Padrón-España), desde el punto de vista antropológico”, VI Coloquio Galaico-Minhoto, 33-56.

CASTELLANOS, S.M. 1996. "Las reliquias de santos y su papel social: cohesion comunitaria y control episcopal en Hispania (ss. V-VII)”. Polis. Revista de ideas y formas de la Antigüedad Clásica. 8, 5-21.

CASTRO PAREDES, I.; INSUA LIÑARES, Ma .J.; LÓPEZ PÉREZ, Mª.C. 2003. "Aportaciones a la arqueología urbana de A Coruña: La Casa Martelo a través de sus materiales”. Brigantium. Boletín do Museo Arqueolóxico e Histórico da Coruña, 14, 225-243.

CHAMOSO LAMAS, M. 1972. "Noticia sobre la importancia arqueológica de Iria Flavia (Padrón-La Coruña)”. Archivo Español de Arqueología, 45-47, 125-134.

CHAMOSO LAMAS, M. 1999. "Noticias relativas al hallazgo de necrópolis paleocristianas en las provincias de Pontevedra y A Coruña”. En Pontevedra no obxectivo de Manuel Chamoso Lamas. pp. 105-108.

CHAVARRÍA ARNAU, A. 2007 El final de las villae en Hispania (s. IV-VII d. C.), Turnhout.

CONSTELA DOCE, X., 2008. "Escavación arqueolóxica en área e decapaxe mecánica no soar do nº 16 da rúa Areal, Vigo”. En M. P. Varela Campos (coord.) Actuación arqueolóxicas. Ano 2006. Santiago de Compostela. pp. 152-153.

CORDEIRO MAANÓN, L.; RODRÍGUEZ CAO, C. 2006. "Escavación no soar $\mathrm{n}^{\circ} 12$ da rúa de San Roque e $\mathrm{n}^{\circ} 5,7,13$ e 15 da rúa Río Neira, Lugo”. En M. P. Varela Campos (coord.) Actuación arqueolóxicas. Ano 2006. Santiago de Compostela. p. 137.

COSTA GARCÍA, J.M.; RODRÍGUEZÁLVAREZ, E.; VARELA GÓMEZ, D. 2011. "Del complejo militar romano al monacato altomedieval: aproximación a las transformaciones del espacio interior galaico entre los siglos I y X d. C. a partir de los asentamientos de A Cidadela (Sobrado dos Monxes, A Coruña)”. Estrat critic. Revista d'Arqueologia, 5, Vol. II, 454-464.

DÍAZ MARTÍNEZ, P.C. 1990. "El monacato y la cristianización del NO hispano. Un proceso de aculturación”. En: Antigüedad y Cristianismo: monografías históricas sobre la antigüedad tardía, 7 , 531-540.

DÍAZ Y DÍAZ, M.C. 1985. Visiones del Más Allá en Galicia durante la Alta Edad Media. Santiago de Compostela.

DÍAZ Y DÍAZ, M.C. 1991. “La cristianización de Galicia”. En R. Villares (dir.) Historia de Galicia. Vigo. pp. 161-176.

FARIÑA BUSTO, F.; SUÁREZ OTERO, J. 1997. “As necrópoles xermano-suévicas”, En Galicia castrexa e romana. Santiago. pp. 304-312.

FERNÁNDEZ FERNÁNDEZ, A. 2014. El comercio tardoantiguo (ss. IV-VI) en el noroeste peninsular a través del registro cerámico de la Ría de Vigo, Oxford.

FERNÁNDEZ FERNÁNDEZ, R. Ma 1993. De las XII tablas al digesto. Estudio sobre la organización de las comunidades romanas. Tesis Doctoral. Universidad del País Vasco.

GARCÍA MARTÍNEZ, M.C.; VÁZQUEZ VARELA, J.M. 1968. "La necrópolis de "Adro Vello" (San Vicente de O Grove)”. Revista Compostellanun, 4, Vol. 13, 563-571.

GARCÍA QUINTELA, M.V. 2015. "La construcción del paisaje cristiano de Galicia: Hacia la definición de un modelo de transformación”. Estudos do Quaternário, 12, 143-159. https://doi.org/10.30893/ eq.voi12.121

GARCÍA QUINTELA, M.V. 2014. "Paisajes duales en la Galicia tradicional: estructura, génesis y transformación”. Revista de dialectología y tradiciones populares, 1, Vol. LXIX, 29-52. https://doi. org/10.3989/rdtp.2014.01.002 
GÓMEZ SOBRINO, J.; GONÁLEZ SANTISO, A.; MARTÍNEZ DO TAMUXE, X. 1980. "La villa romana y necrópolis germániza de Currás-Tomiño”. Separata de Tuy. Museo y archivo diocesano, III, 321-338.

GONZÁLEZ FERNÁNDEZ, X.M. 1985/86. "Las tumbas romanas de Galicia”. Pontevedra Arqueológi$\mathrm{ca}$, II, 209-225.

GONZÁLEZ GARCÍA, C. 2016 "La orientación de las iglesias cristianas en Europa”. En S. Giménez Benítez; C. Gómez, (eds.) Primera Escuela Interamericana de Astronomía Cultural, La Plata.

GRANDAL D'ANGLADE, A.; SERRULLA RECH, F.; TOMAS BOTELLA, V.; PÉREZ-RAMA, M.; GÓMEZ, M.; RAMIL GONZÁLEZ, E. 2015. "Vida y muerte de dos mujeres de Brigantium (NW de Iberia) mediante isótopos estables y antropología forense”, Cadernos do Laboratorio xeolóxico de Laxe, 38, 45-66.

GUERRA CAMPOS, J. 1982. Exploraciones arqueológicas en torno al sepulcro del Apóstol Santiago. Santiago de Compostela.

GUTIERREZ CUENCA, E. 2015. Génesis y evolución del cementerio medieval en Cantabria. Tesis doctoral. Universidad de Cantabria.

HIDALGO CUÑARRO, X.M. 1990-91. "Últimas excavaciones arqueológicas de urgencia en Vigo: castros y yacimientos romanos", Castrelos, 3-4, 191-215.

LÓPEZ-COSTAS, O., LANTES SUÁREZ, O.; MARTÍNEZ CORTIZAS, A. 2014. "Soil and bone: diet and diagenesis in the Roman-Postroman cemetery of A Lanzada (Pontevedra)”. En Macías Vázquez, F.; Díaz Raviña, M.; Barral Silva, M.T. (ed. lit.) Retos y oportunidades en la ciencia del suelo: VI Congreso Ibérico de la Ciencia del Suelo. Santiago de Compostela 22-25 junio, 2014. Santiago de Compostela. pp. 41-44.

LÓPEZ-COSTAS, O.; SÁNCHEZ PARDO, J.C. 2016. "Antropología física, arqueología y desigualdad social en las necrópolis medievales de Galicia: hacia una visión de conjunto”. En J. A. Quirós Castillo (ed.), Demografía, paleopatología y desigualdad social en el Noroeste Peninsular en época medieval, pp. 43-62

LÓPEZ-COSTAS, O.; VARELA LÓPEZ, A. 2008. "Estudio cranométrico comparativo de los esqueletos de la necrópolis romana A Lanzada, Noalla, Pontevedra”. Museo de Pontevedra, 62, 29-48.

LÓPEZ-COSTAS, O. 2015. "Taphonomy and burial context of the Roman/post-Roman funerary areas ( $2^{\text {nd }}$ to $6^{\text {th }}$ centuries AD) of A Lanzada, NW Spain”, Estudos do Quaternário, 12, pp. 55-67. https:// doi.org/10.30893/eq.voi12.111

LÓPEZ-COSTAS, O. 2012. Antropología de los restos óseos humanos de Galicia: estudio de la población romano y medieval gallega. Tesis Doctoral. Universidad de Granada

LÓPEZ PEREIRA, J.E. 1997. “A cristianización da Gallaecia”. En Galicia castrexa e romana. Santiago de Compostela. pp. 282-288.

LÓPEZ QUIROGA, J. 2004. El final de la Antigüedad en la Gallaecia. La transformación de las estructuras de poblamiento entre Miño y Duero (ss. $V$-X). A Coruña.

LÓPEZ QUIROGA, J.; BANGO GARCÍA, C.I. 2005. "Los edificos de culto como elemento morfogenético de transformación del paisaje rural en la Gallaecia y en la Lusitania entre los siglos IV y X", Cuadernos de Prehistoria y Arqueología, 31, 29-60. https://doi.org/10.15366/cupauam2006.32.002

LÓPEZ QUIROGA, J.; LOVELLE, M. R. 1999. "La topografía funeraria 'urbana' en el noroeste de la península ibérica (ss. IV-XI)”. En A. Rodríguez Colmenero (coord.), Los orígenes de la ciudad en el noroeste hispánico. Actas del congreso internacional. Lugo 15-18 mayo, 1996. Vol. II. Lugo. pp. 1395-1411.

LORING GARCÍA, M.I. 1986-87. "La difusión del cristianismo en los medios rurales de la Península Ibérica a finales del Imperio romano". Separata de Studia Histórica Historia Antigua, 1, Vol. IVV, pp.195-204.

MARTÍN VISO, I. 2015. “Espacios funerarios e iglesias en el centro peninsular. Una relación compleja”. En Sabaté i Curull, F.; Brufal, J. (coord.) Arqueología Medieval: Els espais sagrats, Lleida, pp. 81-114.

PÉREZ LOSADA, F. 2002. Entre a Cidade e a Aldea: estudio arqueohistórico dos 'aglomerados secundarios' romanos en Galicia. Brigantium 13. 
PIAY AUGUSTO, D. 2011. “Arqueología y priscilianismo”. Hispania Antiqua, 35, pp. 271-30o.

PIAY AUGUSTO, D. 2016. El Priscilianismo: arqueología y prosopografía. Estudio de un movimiento aristocráticos en la Gallaecia tardorromana. Tesis Doctoral. Universidad de Santiago de Compostela.

RAMIL REGO, E. 1994. El mundo romano en Galicia. Vilalba.

REMESAL RODRÍGUEZ, J. 2001. "Aspectos legales del mundo funerario romano”, En D. Vaquerizo Gil (coord.), Espacios y usos funerarios en el Occidente romano: actas del Congreso Internacional celebrado en la Facultad de Filosofía y Letras de la Universidad de Córdoba. Córdoba 5-9 junio, 2001. Vol. I. Córdoba. pp. 369-377.

RODRÍGUEZ CASAL, A.A.; GONZÁLEZ LOPO, D. 2006. Muerte y ritual funerario en la Historia de Galicia. Santiago de Compostela.

RODRÍGUEZ COLMENERO, A. 1977. Galicia Meridional Romana. Bilbao.

RODRÍGUEZ COLMENERO, A.; CARREÑO GASCÓN, C. 1987 “Cidade de Lugo”, Campaña 1987. Arqueoloxía. Informes 1, Xunta de Galicia, pp. 100-103

RUIZ TRAPERO, M.; DE SANTIAGO FERNÁNDEZ, J.; DE FRANCISCO OLMOS, J.M. 2003. Álbum de láminas de epigrafía latina antigua y medieval, Madrid.

SÁNCHEZ MILÂO, MaC, 2012. "Sobre la necrópolis romana del Campo de la Feria de Lugo: descubrimiento y destrucción del Patrimonio Arqueológico”. CROA. Boletín da Asociación de Amigos do Castro de Viladonga, 22, 20-33.

SÁNCHEZ PARDO, J.C. 2012. "Los contextos de fundación de las iglesias tardoantiguas en Galicia (ss. V-VIII): substratos arqueológicos, distribución y significados”. AnTard (Antiquité tardive. Revue international d'histoire et d'archéologie), 20, pp.255-273. https://doi.org/10.1484/J.AT.1.103107

SÁNCHEZ PARDO, J.C. 2013. "Iglesias y dinámicas sociopolíticas en el paisaje gallego de los siglos VVIII”. Hispania, 243, Vol. LXXIII. 11-50. https://doi.org/10.3989/hispania.2013.001

SÁNCHEZ PARDO, J.C. 2014. “Organización eclesiástica y social en la Galicia tardoantigua. Una perspectiva geográfico-arqueológica del Parroquial Suevo”. Hispania Sacra, 66, 439-480. https://doi. org/10.3989/hs.2014.058

SEVILLA CONDE, A. 2014. Funus Hispaniense: espacios, usos, y costumbres funerarias en la Hispania Romana. Oxford.

TRANOY, A. 1981. La Galice romaine: recherches sur le nord-ouest de la péninsule ibérique dans l'Antiquité. París.

VALDÉS BLANCO-RAJOY, R., 1994. "La Necrópolis tardorromana de Guisande”. Gallaecia: Revista de Arqueoloxía e Antigüidade, 14-15, 469-495.

VALDÉS BLANCO-RAJOY, R., 1995. "La Necrópolis tardorromana de Guisande”. XXII Congreso Nacional de Arqueología, vol. II, Vigo. pp. 337-342.

VALLE ABAD, P. 2017. "Necrópolis costeras del noroeste peninsular durante la antigüedad. Primeros resultados”. En A. Vázquez Martínez, A.; R. Cordeiro Macenlle; M. Carrero Pazos; M. Díaz Rodríguez; A. Rodríguez Nóvoa; B. Vilas Estévez (eds.), (Re)escribindo a Historia. Achegas dos novos investigadores en Arqueoloxía e Ciencias da Antigüidade, Santiago de Compostela, pp. 299-306

VAQUERIZO GIL, D. 2007. "La muerte en la Hispania Romana. Ideología y prácticas”. En F. J. Barca Durán; J. Jiménez Avila (ed. lit.) Enfermedad, muerte y cultura en las sociedades del pasado. Importancia de la contextualización en los estudios paleopatológicos. Actas del VIII Congreso Nacional de Paleopatología-I Encuentro hispano-luso de Paleopatología. Cáceres 16-19 noviembre, 2005. Vol. I. Cáceres, pp.135-158.

VAQUERIZO GIL, D. 2011. "Espacios, usos y hábitos funerarios en la Hispania romana: reflexiones y últimas novedades”. En J. Andreu Pintado; D. Espinosa Espinosa; S. Pastor (coords.) Mors Omnibus Instat. Aspectos arqueológicos epigráficos y rituales de la muerte en el occidente romano, Madrid, pp.197-220.

VAQUERIZO GIL, D. 2011b. “De la agonía al luto. Muerte y funus en la Hispania Romana”. En La muerte en el tiempo. Arqueología e Historia del hecho funerario en la provincia de Toledo. Talavera de la Reina, pp. 95-125. 
VAQUERIZO GIL, D.2011c. "Expresiones privadas en espacios públicos: las áreas funerarias". En M. D. Baena; C. Márquez; D. Vaquerizo (coords.), Córdoba reflejo de Roma. Catálogo de la exposición. Córdoba. pp. 252-257.

VÁZQUEZ GÓMEZ, X.L. 1991. "Últimas actuacións arqueolóxicas na Coruña”. Larouco. Revista da historia primitiva, tradicións orais e patrimonio cultural de Galicia, 1, 131-139.

VÁZQUEZ GÓMEZ, X.L 1996. “Excavación en la Calle de la Franja 9-11. A Coruña”. Gallaecia: Revista de arqueoloxía e antigüidade, 14-15, 411-461.

VIDAL VILAVERDE, M. 1983. "Encol da vila romana e necópolis de Currás". Revista Grial, no 82, T. 21, 501-502.

VIEITO COVELA, S.; PÉREZ LOSADA, F.; FERNÁNDEZ FERNÁNDEZ, A. 2006. "El material cerámico de construcción de la villa y necrópolis de Toralla: tipología y usos”. En C. Fernández Ochoa; V. García-Entero; F. Gil Sendino (eds.) Las villae tardorromanas en el occidente del Imperio: arquitectura y función. IV Coloquio internacional de arqueología en Gijón, Gijón, pp.755-766.

VIGIL-ESCALERA GUIRADO, A. 2013. "Prácticas y ritos funerarios", En J. A Quirós Castillo (coord.) El poblamiento rural de época visigoda en Hispania. Arqueología del campesinado en el interior peninsular, Bilbao, pp. 259-288. 